\title{
Human milk as a potential source for isolation of probiotic lactic acid bacteria: a mini review
}

\author{
${ }^{1 *}$ Mustakim, M., ${ }^{1}$ Sinawat, S., ${ }^{1}$ Salleh, S.N., ${ }^{2}$ Purwati, E., ${ }^{3}$ Alias, R., ${ }^{4}$ Syed Mohamad, S.A. \\ and ${ }^{5}$ Mat Issa, Z. \\ ${ }^{1}$ Centre of Medical Laboratory Technology, Faculty of Health Sciences, Universiti Teknologi MARA \\ (UiTM), Selangor Branch, Puncak Alam Campus, 42300 Bandar Puncak Alam, Selangor, Malaysia. \\ ${ }^{2}$ Faculty of Animal Science, Andalas University, 25163 West Sumatra, Indonesia. \\ ${ }^{3}$ Institute of Bio-IT Selangor, Universiti Selangor, Jalan Zirkon 7A, Seksyen 7, 40000 Shah Alam, Selangor, \\ Malaysia. \\ ${ }^{4}$ Centre of Biology, Faculty of Applied Science, Universiti Teknologi MARA (UiTM), Selangor Branch, Shah \\ Alam Campus, 40000 Shah Alam, Selangor, Malaysia. \\ ${ }^{5}$ Department of Foodservice Management, Faculty of Hotel and Tourism Management, Universiti Teknologi \\ MARA (UiTM), Selangor Branch, Puncak Alam Campus, 42300 Selangor, Malaysia
}

\author{
Article history: \\ Received: 23 December 2018 \\ Received in revised form: 3 \\ May 2019 \\ Accepted: 5 May 2019 \\ Available Online: 14 August \\ 2019
}

\section{Keywords:}

Human milk,

Lactobacillus spp.,

Probiotics

DOI:

https://doi.org/10.26656/fr.2017.4(2).307

\begin{abstract}
Probiotics are living microorganism that can be employed as a new approach to promote human health. These organisms are found to have attractive means for health due to their probiotic properties particularly in generating antimicrobial activity. Lactobacillus spp. is one of the main genera commonly used for probiotic purpose. Human milk is a potential source of Lactobacillus spp. and one of the criteria that found beneficial is that it is of human origin, which could be more reliable sources to be used in human. Lack of studies on isolation of probiotic bacteria from human milk was reported and some probiotic properties show a variation between strains from different regions and population. Therefore, it is important to carry out the isolation of Lactobacillus spp. from a large number of species in the genera to facilitate the finding of the most competent strain to be incorporated as probiotic agent. Moreover, to ensure suitability and compatibility for human use, the probiotic agent originated from human milk should not be an exception. In addition, certain probiotics show a great correlation with prebiotic existed in human milk to boost their function and may suggest an added value to be a suitable candidate as probiotic. This review provides an overview of studies related to human milk as the promising sources for isolation of probiotic microorganisms.
\end{abstract}

\section{Introduction}

\subsection{Human milk composition and prebiotic}

Human milk is a biological fluid which fulfils the nutritional requirement for growth and development of infant (LaTuga et al., 2014; Toscano et al., 2017; Wang et al., 2017). Human milk also supplies various sources of vitamins, minerals as well as micronutrients that required by infant until weaning (Drago et al., 2017; Toscano et al., 2017). Hernell et al. (2016) stated that the concentration of the nutrients and other substances like binding proteins differ between human and animal milk. This difference inspires great interest in the finding of significance micronutrients. The differences demonstrated include the amount of fat, protein, water and presence of anti-infective properties.
Another valuable composition in human milk is oligosaccharides (HMO) which has been found in high concentration and diversity (Katayama, 2016) which also further described that there are between 10 to $20 \mathrm{~g}$ unbound oligosaccharides in one litre of mature human milk. The building blocks of the oligosaccharides comprise of $\mathrm{N}$-acetylglucosamine (GlcNAc), L-fucose (Fuc), D-glucose (Glc), D-galactose (Gal), and $\mathrm{N}$-acetyl neuraminic acid (Neu5Ac). The reducing end builds by lactose (Galb1-4Glc). HMO also have been recognized consist of 130 different types and only trace amounts that are constituted of infant formula which is less complex.

Wang et al. (2016) stated that HMO assists in selective amplification of bacterial population in the infant gut. The result of their study found that HMO plays a prebiotic role for Bifidobacteria by the evidence 
that the presence of several core structures of HMO was positively linked with the relative abundance of the infants' faecal Bifidobacterium. According to Katayama (2016), the most abundant constituent in milk, oligosaccharides range the third after lactose and lipids. Oligosaccharides, for a long time, is believed for not having any biological significance until recent finding found that it is important for infant growth (Alderete et al., 2015; Katayama, 2016; Wang et al., 2016; Charbonneau et al., 2017). Moreover, certain HMOs is derived from the mother's mammary epithelial cells. It shares a similar structure with glycans on neonatal intestinal epithelial cells which commonly to be pathogen's receptor. Such structure provides a defensive approach by the action of glycans acting like decoys and binds to pathogens instead (Chen, 2015; McGuire and McGuire, 2017).

\subsection{Human milk as continuous supply of microbiota}

Traditionally, human milk was believed as sterile but, recent findings revealed that it comprises of constant supply of symbiotic and probiotic potential bacteria to neonates (LaTuga et al., 2014; Toscano et al., 2017; Wang et al., 2017). Medjaoui et al. (2016) emphasized that human milk microbiota could play potential biological role and the result of their findings indicated that bacteria in human milk are not contaminants. This was supported by Fernández et al. (2013) by the fact that bacteria belong to similar genera can be found in fresh human milk of healthy women from various countries which conclude their presence are mutual event (Medjaoui et al., 2016; Drago et al., 2017). It was proven that $800 \mathrm{~mL}$ human milk consumed by neonate through suckling is equivalent to $10^{5}$ to $10^{7}$ of ingested commensal bacteria (Fernández et al., 2013; Medjaoui et al., 2016). Previous studies also inferred that the composition of commensal in infant faecal exhibit similarity with human milk microbiota such as demonstrated by Wang et al. (2016). The latter may function in the prevention of pathogens when supplied to the infant gut. Walker and Lyengar (2015) described that the transient nature of mammary microbiota is somehow unique in which it starts to develop through the last third of pregnancy. Then, the highest complexity reached as the period end, continue constantly during lactation and followed by a sharp fall at weaning. Lastly, as no milk present in the mammary gland, it rapidly disappears, and apoptosis occurs for the purpose of mammary involution.

Biagi et al. (2017) also admitted that there was a controversial issue regarding the bacteria in human milk. In their study, they explained the possible route and pathway to justify the origin of bacteria's presence. They suggested several mechanisms include retrograde flow back during infant suckling, interaction with maternal normal flora on skin, through endogenous route, and contraction of myoepithelial cells. Belstrøm et al. (2014) found that Streptococcus spp. is a dominant genus in human salivary thus indicates that it is one of the significant residents of the salivary microbiome. This result was supported by Posse et al. (2017) in which they stated that Streptococcus spp. was the major genera in infant saliva. Numerous studies were done on bacteria isolated from human milk also revealed the presence of Streptococcus spp. For instance, Jiménez et al. (2015) discovered Streptococcus spp. in human milk of 10 healthy women. Another example a year later, a systematic review executed by Fitzstevens et al. (2016) assessed Streptococcus spp. in human milk as a predominant group including other genera such as Bifidobacterium, Staphylococcus, Enterococcus as well as Lactobacillus. The correlation of these findings proposed that backflow may be the best route for infant's mouth and mammary gland bacteria exchange. The finding verified the hypothesis that maternal milk microbiome may establish salivary members of microbiota or conversely (Pannaraj et al., 2017; Biagi et al., 2017, 2018).

Next, there is a possibility that the origin of bacteria in human milk may be due to interactions with maternal skin normal flora as stated by Biagi et al. (2017). However, there are speculations for this point as they also claim that major differences of bacterial community from both origins do exist. The researchers admitted that bacterial presence in human milk is not simply an outcome of contamination. The statement was supported by several studies done on the isolation of Bifidobacteria from human milk which could not be found in breast skin (Fernández et al., 2013; Chen et al., 2018). In addition, other researchers speculated that the isolates in milk could be from the vaginal origin as the species such as Lactobacillus spp. are dominant in vaginal of healthy women (Mueller et al., 2015; Gritz and Bhandari, 2015; Hendricks-muñoz et al., 2017; Dahl et al., 2018). They suggested that there is a possibility that infant becomes contaminated during delivery and exposed to breast skin while nursing. Moreover, the fact that bacteria in human milk are transmissible from the maternal gut by endogenous route (Rodriguez, 2014). Previously, M cells that situated in Peyer's Patches which is a specialized epithelial cell was thought to be a channel for pathogens with invasion genes expressed to penetrate gut mucosa. Dendritic cells have the ability to open tight junctions of intestinal epithelial cells, transmit dendrites outside and directly fetch bacteria, at the same time maintaining the integrity of the epithelial barrier (Chang et al., 2014). As bacteria was situated in dendritic cells or either other kinds of lymphocyte or macrophages, circulation within 
the lymphoid system which is mucosal associated enable the bacteria to disperse to other location (Chang et al., 2014). Antigen-stimulated to migrate to from intestinal mucosa and occupied in lactating mammary gland as well as others such as respiratory, salivary and genitourinary (Chang et al., 2014).

Furthermore, the occurrence of bacteria in human milk was suggested to be facilitated by contraction of myoepithelial cells during lactation by Martín et al. (2009). They mentioned that lactation occurred through a progression of developmental stages and a great increase in ducts and alveoli occurred due to the hormonal factor. They also stated that the alveolar system lobules are well developed, and small amount colostrum possibly released several weeks before delivery. Both factors, the rise in lymph and blood supply to the gland, as well as the release of oxytocin which cause microepithelial cells contraction may aid in the existence of endogenous bacteria in human milk (Martín et al., 2009).

\subsection{Human milk prevents illnesses}

Human milk has been claimed to have biotherapeutic function as the presence of the commensal bacteria as biotherapeutic agents in the milk is found beneficial (Fernández et al., 2013; Toscano et al., 2017). Heikkila and Saris (2003), pointed out that 'bacteriotherapy' or bacterial interference is suggested as a good alternative in resisting infections. As the commensal bacteria compete for binding site and nutrients, they also produce antimicrobial substances (Heikkila and Saris, 2003), which may be responsible for disease prevention. A study done by Howie et al. (1990), on the protective influence of breastfeeding towards infection, claimed that there is a small decrease in the rates of respiratory illness in infant at age 0 to 13 days and 40 to 42 weeks which have been breastfed for greater than 13 weeks rather than bottle fed. Moreover, based on a study in Latin America by Betrán et al. (2001) suggested that prevention of $13.9 \%$ of infant mortality is possible by exclusive breastfeeding for zero to three months age followed by partial breastfeeding during the first year.

Besides respiratory infections, the risk of diarrhoea has also proved to be associated with breastfeeding and this disease is a leading cause of children mortality (Morrow and Rangel, 2004). According to Black et al. (2003), in developing countries, for less than five years old children, twenty percent of more than 10 million deaths annually were due to diarrhoea. Morrow and Rangel (2004) stated that basically, the attribution of anti -inflammatory, anti-infective and immunoregulatory factors that human milk-transmitted prevent the infection. They also mentioned that breast milk had been proven to prevent diarrhoea caused by bacterial, parasitic as well as viral infection. Breast milk is claimed to have contained lactoferrin, other anti-inflammatory factors and immunoglobulin ( $\operatorname{sgA}$ ). The latter is one of the antibodies which may prevent the invasion of pathogen to intestinal epithelium. It increases rapidly throughout the first six months after birth for infants who breastfed exclusively rather than those bottle-fed. Howie et al. (1990) concluded in their study that breastfeeding throughout the first 13 weeks of life contributes to longer protection against gastrointestinal illness. Furthermore, Scariati et al. (1997) claimed that protection against diarrhoea and ear infection was among the benefit conferred by breastfeeding. They performed a longitudinal analysis to verify whether breastfeeding was able to protect US infants from diarrhoea and ear infection. Their study inferred that the risk of diarrhoea was significant to infant who did not receive breast milk compared to breastfed infant. Similarly, non-breast fed infant was also more likely to develop ear infection (Scariati et al., 1997).

\section{Lactic acid bacteria (LAB)}

The terms "lactic acid bacteria" were implemented at the turn of the 20th century, which refer to "milk-souring organism" (Lahtinen et al., 2012; Pessione, 2012; Gupta et al., 2018). LAB consists of extensive range genera with a substantial number of species having characteristics which include Gram-positive, catalase negative, are either obligate anaerobe or microaerophilic as well as the absence of endospore (Mokoena, 2017; Gupta et al., 2018). Lactobacillus, Enterococcus, Pediococcus, Lactococcus, Leuconostoc, Streptococcus, Carnobacterium, Weissella and Bifidobacterium are the most significant genera of LAB whereas the chosen strains for probiotics commonly are from the species of Lactobacillus, Bifidobacterium and Enterococcus (Klein et al., 1998; Evivie et al., 2017). LAB are traditionally used in fermented food product preservation (Holzapfel et al., 2001; Douillard and de Vos, 2014). LAB do not have a functional respiratory system thus, gain their energy by substrate-level phosphorylation (Lahtinen et al., 2012). LAB possess two different carbohydrate fermentation patterns, which are homolactic and heterolactic fermentation pathways. The homolactic pathway or Embden-Meyerhof-Parnas pathway through glycolysis produce lactic acid as the only yield. In contrast, the heterolactic pathway produced lactic acid, $\mathrm{CO}_{2}$ and either ethanol or acetate. Basically, homolactic pathway yield 2 moles of ATP per mole of glucose whereas only 1 mole of ATP produced in heterolactic pathway in case of reduction of acetyl phosphate that forms as intermediate to ethanol. Though, an extra formation of ATP is possible if acetyl phosphate is converted to acetic acid as alternative electron acceptors 
present. The genera in $\mathrm{LAB}$ can be further divided based on fermentation type into obligate heterofermentative, obligate homofermentative and facultatively heterofermentative lactobacilli.

\subsection{Lactobacillus spp.}

The genus of Lactobacillus was established by Beijerinck in 1901. Lactobacillus spp. are the major group of LAB which consists of 196 validly published species as of May 2018 (Huang et al., 2018). It is characterized as Gram-positive, rod-shaped, catalase negative, and non-spore forming. For decades, the classification and nomenclature of lactobacilli have been according to phenotypic properties. They were classified into three subgenera, 'Thermobacterium', 'Streptobacterium', and 'Betabacterium' (Klein et al., 1998 as cited in Kandler and Weiss, 1986; De Angelis and Gobbetti, 2016), based on growth temperatures hexose fermentation pathway either homofermentative or heterofermentative (Klein et al., 1998; Rajili and Vos, 2014; De Angelis and Gobbetti, 2016). However, division by subgenera was no longer valid as modern molecular approaches demonstrate inconsistency with species phylogenetic relationship (Goldstein et al., 2015; De Angelis and Gobbetti, 2016).

These lactobacilli are applicable as starter cultures in the fermentation of food as they promote fermented food conservation, texture and taste. Lactobacillus spp. may be found in human and animals gut, the variation of their number may be due to several factors such as host age and host species as well as the site within the gut (de Vries et al., 2006; Mokoena, 2017). Due to many benefits obtained from this genus, many studies were conducted on the isolation of Lactobacillus spp. from various sources and some were tested for probiotics (Shokryazdan et al., 2014). Lactobacillus brevis and Lactobacillus fermentum were isolated from human milk (Sallam et al., 2015). Ramasamy and Suyambulingam (2015) investigated on Lactobacillus fermentum isolated from traditional fermented dairy products. Besides that, isolation of the bacteria from commercial yoghurt (Herbel et al., 2013) and camel milk (Hamed and Elattar, 2013) have also been done.

\section{Identification of Lactobacillus spp.}

3.1 Phenotypic and genotypic identification of Lactobacillus spp.

A study by Huang et al. (2018) pointed out that physiological and biochemical classifications and characterization of lactobacilli are ambiguous and timeconsuming also they do not always equivalent to real genetic relativity of the species. They also agreed that biochemical characterization was not fully discriminative for strains distinguishing purposes. It was admitted that API $50 \mathrm{CH}$ kits allowed rapid analysis but it did not contribute to complete consistent result of phenotypic identification as mentioned by Dimitonova et al. (2008) since their finding reveals the limitation of the method. Phenotypic characteristics are identified from the morphology of colonies on MRS agar, Gram staining and biochemical analysis included catalase and oxidase tests (Serrano-Niño et al., 2016). Lactobacillus spp. characterized as Gram-positive, rod-shaped, catalase negative, oxidase negative and non-spore forming. Tormo et al. (2015) also reported on the limitation of this approach in which their finding reveals that 6 strains of Lactobacillus lactis cremoris detected by PCR were not being identified by using API test. Similar incongruity situation reported for Lactobacillus crispatus which determined as Lactobacillus acidophilus by API test. The test may lead to provocative results and the reliability was being argued (Brolazo et al., 2011). Bahrami and Sjöholm (2016) supported that characterization by API $50 \mathrm{CH}$ is not reliable enough by the fact that the database is not updated, and some new species are not available.

Identification method for lactobacilli has recently enhanced by molecular approaches (De Angelis and Gobbetti, 2016; Alrubaye et al., 2018). For instance, polymerase chain reaction (PCR), DNA sequencing, multiplex PCR, fluorescent in situ hybridization (FISH), pulsed-field gel electrophoresis (PFGE), ribotyping, randomly amplified polymorphic DNA (RAPD) and amplified fragment length polymorphism (AFLP) (De Angelis and Gobbetti, 2016; Nemska et al., 2017). A finding by Nemska et al. (2017) proved that RAPD-PCR technique is fast, inexpensive, and contribute to good discrimination level of Lactobacillus spp. as well as enabling new isolated strains subtyping. Distinctive strain-specific characteristics of representatives of Lactobacillus plantarum group were tested in their study.

\section{LAB from human milk}

Initial evolution possesses an important role in the establishment of the GI microbiota and immune system maturation. If the process is being interrupted, there will be higher chances of diseases in later life. Breast milk is considered as the major contributing postnatal factor in microbiome, metabolome and immunological programming (Amenu, 2014; Abubakr, 2018). A large body of literature has investigated the effect of human milk on the health of infants; however, few writers have been able to draw on any systematic research into the microbiology of breast milk. From the few studies, human milk is found to be a significant source for potential probiotic strains to the infant's gut. 
A study by Kozak et al. (2015) revealed that a set of lactic acid bacteria which included Lactobacillus, Bifidobacteria and Enterococcus was the most common genera found in breastfed infants faeces. This is consistent with another finding by this group of scientists that the mentioned set of LAB is among the first microbes to colonize the infant gut after birth (Kozak et al., 2015). However, a large scale study by Chen et al. (2018) reaches different conclusions, finding their data opposing the idea of lactobacilli and bifidobacteria are common and abundant in milk samples. They conclude that each milk samples possessed a unique profile and patterns of bacterial abundance levels (Chen et al., 2018). A relationship exists between mother's milk and infant's faeces as the bacterial composition of the faecal microbiota of the breastfed infant usually reflects that of breast milk. Similarly, Medjaoui et al. (2016) have attempted to isolate LAB from human milk and newborn faeces. They isolated Enterococcus and Lactobacillus from breast milk and infant faeces samples of 20 motherinfant pairs and found that Enterococcus faecalis and Enterococcus faecium were shared among several mother-infant pairs. This suggests that breast milk could contribute to the infant gut colonization.

Regarding gut colonization, Damaceno et al. (2017) questions that despite the optimal nutritional and physicochemical conditions of maternal milk in the mammary glands for bacterial growth, LAB population is maintained in a relatively low concentration. They highlighted the possibility of a correlation between lipids and bacterial population in human milk. This is supported by Kumar et al. (2016) who found that the Firmicutes phylum was positively associated with BMI for more than $98 \%$ of women independent of country origin (Spain, Finland, South Africa and China). They had examined the extent to which Lactobacillus genus was significantly associated with monounsaturated fatty acids (Kumar et al., 2016).

Besides that, several other factors have been noted by various researchers to have influenced $\mathrm{LAB}$ composition in human breast milk. In an analysis of probiotic properties of LAB isolated from human milk, Reis et al. (2016) found that the 33 LAB isolated from six breast milk samples could be influenced by various factors including nutritional habits, genetics, intestinal microbiota, health, weight, type of delivery, use of antibiotics and gestational age of lactating women (Reis et al., 2016). In another major study, Soto et al. (2014) reported that the number of lactobacilli-bifidobacteria isolated was significantly lower in women who had received anti-biotherapy during pregnancy or lactation. Several studies also have revealed that LAB is predominantly isolated from samples collected after a vaginally delivered partum compared to caesarean section (Medjaoui et al., 2016; Damaceno et al., 2017). However, in their novel study on isolation of Bifidobacteria from human milk, Huidrom and Sharma (2018) found that there is no correlation between the age of lactating women with the presence or absence of Bifidobacterium in their milk.

\section{Probiotic properties}

There was extensive research on probiotic potential properties of LAB has been reported. The theory of probiotic LAB bacteria as biotherapeutic agents seems to capture huge interest. Due to the properties of certain LAB as a health booster, functional food like fermented milk and yoghurts claim to be incorporated with probiotics are expanding (Wedajo, 2015; Thakur et al., 2016; Evivie et al., 2017; Gupta et al., 2018). Nevertheless, establishing the effect and effectiveness of probiotic strain is not that simple (Thakur et al., 2016) as several requirements were found to be essential for effective probiotics (Wedajo, 2015; Thakur et al., 2016). Gupta et al. (2018) outlined the key requirements for excellent probiotic into four aspects which were safety, functional, technological and beneficial features. The safety aspect included specifications which were the origin, lack of harmful activities and absence of acquired antibiotic resistance. Besides, they claimed that viability in the gastrointestinal tract, excellent adherence and colonization of the gut as well as validated and documented health effects as important functional aspects. Meanwhile, antagonistic action, as well as antimutagenic, antihaemolytic and anticarcinogenic characteristics, are specifications included in beneficial aspects (Gupta et al., 2018). Fuochi et al. (2015) claimed four requirements for a potential probiotic should have which include ability to attach to epithelial cell and stay alive for colonization of human gut, ability to effectively compete with pathogenic bacteria already present in the gut, ability to affect enzymatic modification of antimicrobial compounds and ability to improve immune defences against harmful microorganism. These criteria are corresponding and agreed by other researchers (Wedajo, 2015; Shi et al., 2016; Thakur et al., 2016; Evivie et al., 2017; Gupta et al., 2018). The fact that it must be originated from human origin is being argued. It was generally accepted that probiotics strain used for human applications should be originated from humans as studies found that probiotic strains were host specific (Ranadheera et al., 2014; Wedajo, 2015; Thakur et al., 2016).

Furthermore, probiotic strains should have a high survival rate in the human gastrointestinal tract. Orally intake of probiotics cause the bacteria to encounter 
secretion associated human defence systems which include mucins that present in high concentrations, low $\mathrm{pH}$ environment due to gastric acid, as well as secretion of bile salts in the proximal small intestine (Quinto et al., 2014; Wedajo, 2015; Gupta et al., 2018). The ability to resist gastric acidity is one of the functional properties and also a significant test which can be done in vitro and often suggested to evaluate probiotic properties of bacteria (Vinderola et al., 2017; Gupta et al., 2018). This is because the introduction to gastric and intestinal fluids is the major environmental stress that reduces probiotics viability took orally (Pisano et al., 2014). LAB tolerance to acids is claimed to be associated with $\mathrm{H}+-$ ATPase activity (Jin et al., 2016). Thus, it can be justified that the varying results of acid tolerance among probiotics may be due to variance in $\mathrm{H}+-$ ATPase activity exerted by each species.

Furthermore, Angmo et al. (2016) stated that bile salts disorganize cell membrane structure and thus, toxic to living cells. Bile salt resistance is believed as a significant characteristic that probiotic should possess. In the duodenum, LAB can be resistance to the toxicity of the conjugated bile salts by bile salt hydrolytic activity (BSH) and allowing colonization (Öner et al. 2014). Some strains of $L$. casei, as well as L. fermentum, have been discovered to excrete bile salt hydrolase which is an enzyme involved in glycine and taurine-conjugated bile salts hydrolysis into free bile salts and amino acid residues (Öner et al. 2014). Kergourlay et al. (2012), revealed certain genes significant for acid tolerance and bile salt resistance in L. salivarius SMXD51 were found in the bacteria genome. These include cholylglycine hydrolase, a bile salt hydrolase family protein and ornithine decarboxylation-antiporter system which may contribute to the ability of the species to withstand gastrointestinal conditions. In an investigation into potential probiotic role of LAB isolated from human milk, Serrano-Niño et al. (2016) found that $L$. fermentum, L. mesenteroides and $L$. delbrueckii subsp. bulgaricus showed tolerance to the acidic conditions $(\mathrm{pH}$ 2 and 3 ) and to bile salt concentration of $0.2 \%$ and $0.4 \%$ $(\mathrm{w} / \mathrm{v})$. This finding is complemented by Reis's et al. (2016) study of probiotic properties of LAB isolated from human milk, in which they note that $71 \%$ of the isolates showed growth at $\mathrm{pH} 3.0$ and 13 isolates showed growth in the medium containing various concentration of bile salts. Interestingly, a detailed evaluation of Lactobacillus spp. resistance to low $\mathrm{pH}$ and bile salts by Fuochi et al. (2015) showed that the isolate from commercial product did not show tolerance to both low $\mathrm{pH}$ and bile salts.

Another significant prerequisite for probiotics activity is adhesion to intestinal surface and colonization of the gut. Adhesion enhances longer persistence of the strain in the intestine and this creates a favourable effect as better metabolic and immunomodulatory effects are possible. Besides, adhesion properties enable competition with pathogenic bacteria and capable of providing immune effects mediation as adhesion enables interaction with the mucosal surface which then facilitates contact with gut lymphoid tissue. All of these explanations were described by Gupta et al. (2018). Commonly, Caco-2 cells have been frequently used to observe adhesion of Lactobacillus spp. of mother's breast milk in in vitro studies (Pisano et al., 2014; Kozak et al., 2015). The adhesion of the species to the epithelial cells can avoid pathogen invasion.

Antagonistic properties are the ability of the probiotic strains to show antimicrobial activity against pathogenic bacteria by means of antimicrobial substance such as bacteriocin (Gupta et al., 2018) as well as other end products metabolites like organic acid, hydrogen peroxide and ethanol (Nallala et al., 2014; Gupta et al., 2018). Inhibition of the growth of pathogen at refrigerated temperatures is possible by the production of hydrogen peroxide (Gupta et al., 2018). This attractive finding can be used in food production. Recently, Serrano-Niño et al. (2016), in their study found that all Lactobacillus spp. isolated from human milk showed positive inhibition to $S$. aureus, E. coli, Salmonella spp., and Listeria spp. However, In a study which set out to determine potential probiotics isolated from human milk and colostrum, Damaceno et al. (2017) reported that $L$. gasseri, $S$. salivarius and $B$. breve did not show antagonistic properties; the isolates agglutinated pathogens instead.

To infer, researchers have recommended several guidelines for safety assessment of probiotics and these were summarized by Gupta et al. (2018) into eight important features which consisted of species and genus origin, safety properties of the strain, stability and viability during storage and manufacturing, ability to resist environmental stress in gastrointestinal tract, adhesion and colonization into the gut, immune response modulation, antibiotic resistance and antimicrobial activity against pathogen.

\section{Antibiotic resistance in LAB}

Natural resistance of the body towards infection can be enhanced by consuming probiotics. Antimicrobial resistance is defined as bacteria survival and growth ability in the presence of chemical molecule either can kill or cause growth limitation (Fraqueza, 2015). Despite the significant function in invading pathogen, the safety aspect of the probiotics in terms of inability for 
transmission of potential antibiotic resistance is vital. The reason is due to the emerging occurrence of antibiotic resistance. As of recently, there has been a spike in studies regarding the characterization of antimicrobial resistance features and probiotics as a source of antibiotic resistance genes ( $\mathrm{Gad}$ et al., 2014; Anjum, 2015; Guo et al., 2017; Almakki et al., 2017). Some of the researchers admitted that there are lactic acid bacteria (LAB) recognized as a reservoir for antibiotic resistance (AR) genes detected and they are transmitted horizontally to pathogen via food chain ( Gad et al., 2014; Fraqueza, 2015; Munita and Arias, 2016). Moreover, the resistance factor can be explained by either intrinsic or natural and acquired resistance. Intrinsic means a natural inherent resistance present in respective strains whereas the latter represents the possibility of horizontal transmission between bacteria which causes initially susceptible bacteria to develop antimicrobial resistance (Fraqueza, 2015; Munita and Arias, 2016). More to the point, acquired resistance may be caused by a result of added genes which included acquiring of exogenous DNA, exchange of gene or indigenous gene mutation (Fraqueza, 2015; Munita and Arias, 2016).

According to Jose et al. (2015), the absence of transferable antibiotic resistance gene is the key requirement for probiotics. Probiotics are considered inapplicable for human or animal use if they are of antibiotic resistance plasmids harbouring strains except for intrinsic antibiotic resistance strains which found to be beneficial for patient who has an imbalance or reduced number of intestinal flora due to antimicrobial agent's administration (Jose et al., 2015). Reis et al. (2016) reported that gentamicin, ampicillin and vancomycin gene resistance has been discovered in $\mathrm{LAB}$ isolates isolated from human milk. Bad consequences may occur if probiotics of antibiotic resistance strains are commercialized in which allows the transfer of resistance gene to intestinal pathogenic microorganisms. Furthermore, several studies were done to rule out the susceptibility of LAB against various antimicrobial agents. Kozak et al. (2015) studied on antibiotic susceptibility of LAB from mother's breast milk and their respective infant stools. The antibiotics assessed include ampicillin, chloramphenicol, clindamycin, erythromycin, gentamicin, tetracycline and vancomycin. They found that 57 out of 59 bacterial isolates from breast milk were resistant to one or more of the antibiotics assessed. Several distinct LAB species isolated showed resistance towards specific antimicrobial agents. For example, Bifidobacterium boum was resistant to tetracycline and others resistant to between 3 to 7 antibiotics. In addition, most Lactobacillus isolates from infant stools were resistant to one to three antibiotics tested (Kozak et al., 2015).

Research by Dec et al. (2015) revealed that high intrinsic resistance to ampicillin, amoxicillin, inhibitors of protein synthesis, fluoroquinolone inhibitors of replication, neomycin, tetracycline, lincomycin, doxycycline, tylosin, flumequine and enrofloxacin were observed in Lactobacillus strain. A similar study was also done by Sornplang et al. (2016) to investigate the susceptibility of 93 Lactobacillus strains to seven antimicrobial agents and found that more than $50 \%$ of Lactobacillus species were intrinsically resistant to vancomycin, streptomycin, ciprofloxacin, and sulfamethoxazole-trimethoprim. A study was done by Dubourg et al. (2015) to characterize the susceptibility levels of Lactobacillus spp. against antimicrobial agents showed species dependent outcomes. Various studies result may create a conclusion which it is obvious that intergenic and interspecies variances and dissimilarities exist. Mathur and Singh (2005), suggested that with the intention to clarify phenotypic susceptibility data, identification at species level was necessary and probiotic should not carry resistance gene except that required as well as not designed to permit extra resistance in order to avoid undesirable resistance transmission.

\section{Conclusion}

Human physiology and health are hugely affected by the expansive network of the human microbiome communities as they colonize various niches within the human body. Homeostasis development and health maintenance are thought to be critically dependent on gut barrier formation by microbiota. In regard to this, research on LAB to be applied as probiotics have exponentially increased in recent years resulting in the development of various food products that benefit health. This review has highlighted some of the areas focusing onto the genus Lactobacillus spp. and associating these bacterial strains with human breast milk. From this literature, it can be concluded that human milk is vital for its role in mediating potentially pathogenic gut microbiota especially for the promotion of infant growth and for its components such as HMO which proved beneficial supplementary to antimicrobial therapy. Moreover, the literal analysis of LAB undertaken here has extended our knowledge of its properties to be used as probiotics and improved the understanding of its role in enhancing human natural resistance towards infection.

\section{Conflict of Interest}

We declare that we have no conflict of interest. 


\section{Acknowledgments}

The authors wish to thank the Institute of Research Management and Innovation (IRMI), Institute of Leadership and Development (ILD) and Institute of Quality and Knowledge Advancement (InQKA) Universiti Teknologi MARA. This project is funded by BESTARI Perdana grant \#600-IRMI/DANA 5/3/ BESTARI (P) (024/2018).

\section{References}

Abubakr, M.A.S. (2018). Antimicrobial Activities of Lactic Acid Bacteria Strains Isolated from Human Breast Milk Against Human Pathogenic Strains. International Journal of Clinical and Development Anatomy, 4(1), 27-31. https://doi.org/ 10.11648/ j.ijcda.20180401.14

Alderete, T.L., Autran, C., Brekke, B.E., Knight, R., Bode, L., Goran, M.I. and Fields, D.A. (2015). Associations between human milk oligosaccharides and infant body composition in the first 6 mo of life. The American Journal of Clinical Nutrition, 102(6), 1381-1388. https://doi.org/10.3945/ ajen.115.115451.1

Almakki, A., Estèves, K., Vanhove, A.S., Mosser, T., Aujoulat, F., Marchandin, H., Toubiana, M., Monfort, P., Jumas-Bilak, E. and Licznar-Fajardo, P. (2017). A new methodology to assess antimicrobial resistance of bacteria in coastal waters; pilot study in a Mediterranean hydrosystem. Comptes Rendus Geoscience, 349(6-7), 310-318. https:// doi.org/10.1016/j.crte.2017.09.009

Alrubaye, H.H., Fakhry, S.S. and Jebur, Z.A. (2018). Biochemical and Molecular Characterization of Lactobacillus spp. isolated from Dairy Products. JSM Microbiology, 6(1), 1048.

Amenu, D. (2014). Probiotic Properties of Lactic Acid Bacteria from Human Milk. Journal of Medical Microbiology and Diagnosis, 3, 005. https:// doi.org/10.4172/2161-0703.S3-005

Angmo, K., Kumari, A., Savitri. and Bhalla, T.C. (2016). Probiotic characterization of lactic acid bacteria isolated from fermented foods and beverage of Ladakh. LWT - Food Science and Technology, 66, 428-435. https://doi.org/10.1016/j.lwt.2015.10.057

Anjum, M.F. (2015). Screening methods for the detection of antimicrobial resistance genes present in bacterial isolates and the microbiota. Future Microbiology, 10(3), 317-320. https:// doi.org/10.2217/FMB.15.2

Bahrami, B. and Sjöholm, B. (2016). Prevalence and Identification of Lactobacillus Species Isolated from
Infected Root Canals by MALDI-TOF Mass Spectrometry, 16S rRNA Gene Sequencing and API 50 CHL. Retrieved from website: https:// pdfs.semanticscholar.org/2267/96c70248a60f87357c 2f0021bf952704cf28.pdf

Belstrøm, D., Holmstrup, P., Nielsen, C.H., Kirkby, N., Twetman, S., Heitmann, B.L. and Klepac-ceraj, V. (2014). Bacterial profiles of saliva in relation to diet, lifestyle factors, and socioeconomic status. Journal of Oral Microbiology, 6(1), 1-10. https:// doi.org/10.3402/jom.v6.23609

Betrán, A.P., de Onís, M., Lauer, J.A. and Villar, J. (2001). Ecological study of effect of breast feeding on infant mortality in Latin America. BMJ, 323, 1-5. https://doi.org/10.1136/bmj.323.7308.303

Biagi, E., Aceti, A., Quercia, S., Beghetti, I., Rampelli, S., Turroni, S., Soverini, M., Zambrini, A.V., Faldella, G., Candela, M., Corvaglia, L. and Brigidi, P. (2018). Microbial Community Dynamics in Mother's Milk and Infant's Mouth and Gut in Moderately Preterm Infants. Frontiers in Microbiology, 2018, 1-10. https://doi.org/10.3389/ fmicb.2018.02512

Biagi, E., Quercia, S., Aceti, A., Beghetti, I., Rampelli, S., Turroni, S., Faldella, G., Candela, M., Brigidi, P. and Corvaglia, L. (2017). The bacterial ecosystem of mother's milk and infant's mouth and gut. Frontiers in Microbiology, 2017, 1-9. https://doi.org/10.3389/ fmicb.2017.01214

Black, R.E., Morris, S.S. and Bryce, J. (2003). Where and why are 10 million children dying every year?. The Lancet, 361(9376), 2226-2234. https:// doi.org/10.1016/S0140-6736(03)13779-8

Brolazo, E.M., Leite, D.S., Tiba, M.R., Villarroel, M., Marconi, C. and Simoes, J.A. (2011). Correlation between API $50 \mathrm{CH}$ and Multiplex Polymerase Chain Reaction for the Identification of Vaginal Lactobacilli in Isolates. Brazilian Journal of Microbiology, 42, 225-232. https://doi.org/10.1590/ S1517-83822011000100028

Chang, S.Y., Ko, H.J. and Kweon, M.N. (2014). Mucosal dendritic cells shape mucosal immunity. Experimental and Molecular Medicine, 46(3), e84e87. https://doi.org/10.1038/emm.2014.16

Charbonneau, M.R., Donnell, D.O., Blanton, L.V, Totten, S.M., Davis, J.C.C., Barratt, M.J., Cheng, J., Guruge, J., Talcott, M., Bain, J.R., Muehlbauer, M.J., IIkayeva, O., Wu, C., Stuckmeyer, T., Barile, D., Mangani, C., Jorgensen, J., Fan, Y.-M., Maleta, K., Dewey, K.G., Ashorn, P., Newgard, C.B., Lebrilla, C., Mills, D.A. and Gordon, J.I. (2017). Sialylated milk oligosaccharides promote microbiota -dependent growth in models of infant 
undernutrition. Cell, 164(5), 859-871. https:// doi.org/10.1016/j.cell.2016.01.024.

Chen, P.W., Lin, Y.L. and Huang, M.L. (2018). Profiles of commensal and opportunistic bacteria in human milk from healthy donors in Taiwan. Journal of Food and Drug Analysis, 26(4), 1235-1244. https:// doi.org/10.1016/j.jfda.2018.03.004

Chen, X. (2015). Human Milk Oligosaccharides (HMOS). In Baker, D.C. and Horton, D. (Eds.) Advances in Carbohydrate Chemistry and Biochemistry. $1^{\text {st }}$ ed. Vol. 72, p. 113-190. USA: Elsevier Inc. https://doi.org/10.1016/ bs.accb.2015.08.002

Dahl, C., Stigum, H., Valeur, J., Iszatt, N., Lenters, V., Peddada, S., Bjørnholt, J., Midtvedt, T., Mandal, S. and Eggesbø, M. (2018). Preterm infants have distinct microbiomes not explained by mode of delivery, breastfeeding duration or antibiotic exposure. International Journal of Epidemiology, 47 (5), 1-12. https://doi.org/10.1093/ije/dyy064

Damaceno, Q.S., Souza, J.P., Nicoli, J.R., Paula, R.L., Assis, G.B., Figueiredo, H.C., Azevedo, V. and Martins, F.S. (2017). Evaluation of Potential Probiotics Isolated from Human Milk and Colostrum. Probiotics and Antimicrobial Proteins, 9 (4), 371-379. https://doi.org/10.1007/s12602-0179270-1

De Angelis, M. and Gobbetti, M. (2016). Lactobacillus spp. General Characteristics. In Reference Module in Food Science. USA: Elsevier. https:// doi.org/10.1016/B978-0-08-100596-5.00851-9

Dec, M., Wernicki, A., Puchalski, A. and Urban-Chmiel, R. (2015). Antibiotic susceptibility of Lactobacillus strains isolated from domestic geese. British Poultry Science, 56(4), 416-424. https:// doi.org/10.1080/00071668.2015.1058919

Dimitonova, S.P., Bakalov, B.V., AleksandrovaGeorgieva, R.N. and Danova, S.T. (2008). Phenotypic and molecular identification of lactobacilli isolated from vaginal secretions. Journal of Microbiology, Immunology, and Infection, 41(6), 469-477.

Drago, L., Toscano, M., De Grandi, R., Grossi, E., Padovani, E.M. and Peroni, D.G. (2017). Microbiota network and mathematic microbe mutualism in colostrum and mature milk collected in two different geographic areas: Italy versus Burundi. ISME Journal, 11(4), 875-884. https://doi.org/10.1038/ ismej.2016.183

Dubourg, G., Elsawi, Z. and Raoult, D. (2015). Assessment of the in vitro antimicrobial activity of Lactobacillus species for identifying new potential antibiotics. International Journal of Antimicrobial Agents, 46(5), 590-593. https://doi.org/10.1016/ j.ijantimicag.2015.05.011

Evivie, S.E., Huo, G.C., Igene, J.O. and Bian, X. (2017). Some current applications, limitations and future perspectives of lactic acid bacteria as probiotics. Food and Nutrition Research, 61, 1318034. https:// doi.org/10.1080/16546628.2017.1318034

Fernández, L., Langa, S., Martín, V., Maldonado, A., Jiménez, E., Martín, R. and Rodríguez, J. M. (2013). The human milk microbiota: Origin and potential roles in health and disease. Pharmacological Research, 69(1), 1-10. https://doi.org/10.1016/ j.phrs.2012.09.001

Fitzstevens, J.L., Smith, K.C., Hagadorn, J.I., Caimano, M.J., Matson, A.P. and Brownell, E.A. (2016). Systematic Review of the Human Milk Microbiota. Nutrition in Clinical Practice, 32(3), 354-364. https://doi.org/10.1177/0884533616670150

Fraqueza, M.J. (2015). Antibiotic resistance of lactic acid bacteria isolated from dry-fermented sausages. International Journal of Food Microbiology, 212, 76 -88 .

j.ijfoodmicro.2015.04.035

Fuochi, V., Petronio, G.P., Lissandrello, E. and Furneri, P.M. (2015). Evaluation of resistance to low $\mathrm{pH}$ and bile salts of human Lactobacillus spp. isolates. International Journal of Immunopathology and Pharmacology, 28(3), 426-433. https:// doi.org/10.1177/0394632015590948

Gad, G.F.M., Abdel-Hamid, A.M. and Farag, Z.S.H. (2014). Antibiotic resistance in lactic acid bacteria isolated from some pharmaceutical and dairy products. Brazilian Journal of Microbiology, 45(1), 25-33. https://doi.org/10.1590/S151783822014000100005

Goldstein, E.J.C., Tyrrell, K.L. and Citron, D.M. (2015). Lactobacillus Species: Taxonomic Complexity and Controversial Susceptibilities. Clinical Infectious Diseases, 60(Suppl. 2), S98-S107. https:// doi.org/10.1093/cid/civ072

Gritz, E.C. and Bhandari, V. (2015). Corrigendum: The Human Neonatal Gut Microbiome: A Brief Review. Frontiers in Pediatrics, 2015, 1-12. https://doi.org/ 10.3389/fped.2015.00060. eCollection 2015.

Guo, H., Pan, L., Li, L., Lu, J., Kwok, L., Menghe, B., Zhang, H. and Zhang, W. (2017). Characterization of Antibiotic Resistance Genes from Lactobacillus Isolated from Traditional Dairy Products. Journal of Food Science, 82(3), 724-730. https:// doi.org/10.1111/1750-3841.13645

Gupta, R., Jeevaratnam, K. and Fatima, A. (2018). Lactic 
Acid Bacteria: Probiotic Characteristic, Selection Criteria, and its Role in Human Health (A Review). Journal of Emerging Technologies and Innovative Research, 5(10), 411-424.

Hamed, E. and Elattar, A. (2013). Identification and Some Probiotic Potential of Lactic Acid Bacteria Isolated From Egyptian Camels Milk. Life Science Journal, 10(1), 1952-1961.

Heikkila, M.P. and Saris, P.E.J. (2003). Inhibition of Staphylococcus aureus by the commensal bacteria of human milk. Journal of Applied Microbiology, 95 (3), 471-478. https://doi.org/10.1046/j.13652672.2003.02002.x

Hendricks-Muñoz, K.D., Xu, J., Parikh, H.I., Xu, P., Thacker, L.R. and Sheth, N.U. (2017). Skin-to-Skin Care and the Development of the Preterm Infant Oral Microbiome. American Journal to Perintalogy, 32 (13), 1205-1216. https://doi.org/10.1055/s-00351552941.

Herbel, S.R., Lauzat, B., von Nickisch-Rosenegk, M., Kuhn, M., Murugaiyan, J., Wieler, L.H. and Guenther, S. (2013). Species-specific quantification of probiotic lactobacilli in yoghurt by quantitative real-time PCR. Journal of Applied Microbiology, 115(6), 1402-1410. https://doi.org/10.1111/ jam.12341

Hernell, O., Timby, N. and Domell, M. (2016). Clinical Benefits of Milk Fat Globule Membranes for Infants and Children. The Journal of Pediatrics, 173 (Suppl.), S60-S65. https://doi.org/10.1016/ j.jpeds.2016.02.077

Holzapfel, W.H., Haberer, P., Geisen, R. and Schillinger, U. (2001). Taxonomy and important features of probiotic microorganisms in physiologic properties of lactic acid bacteria,. The American Journal of Clinical Nutrition, 73(2), 365S-373S. https:// doi.org/10.1093/ajcn/73.2.365s

Howie, P.W., Forsyth, J.S., Ogston, S.A., Clark, A. and Florey, C.D. (1990). Protective effect of breast feeding against infection. British Medical Journal, 300, 11-16. Retrieved from http://www.simpathy.eu/ sites/default/files/a-review-of-literature-andguidance-across-the-eu.pdf. https://doi.org/10.1136/ bmj.300.6716.11

Huang, C.H., Li, S.W., Huang, L. and Watanabe, K. (2018). Identification and classification for the Lactobacillus casei group. Frontiers in Microbiology, 2018, 1-13. https://doi.org/10.3389/ fmicb.2018.01974

Huidrom, S. and Sharma, N. (2018). Isolation and Screening of Novel Isolates of Bifidobacteria from Human Milk as Potential Probiotic with
Antidiarrheal Activity. Annals of Applied Microbiology and Biotechnology Journal, 2(1), 1-8.

Jiménez, E., De Andrés, J., Manrique, M., Pareja-Tobes, P., Tobes, R., Martínez-Blanch, J.F., Codoner, F.M., Ramon, D., Fernandex, L. and Rodríguez, J.M. (2015). Metagenomic analysis of milk of healthy and mastitis-suffering women. Journal of Human Lactation, 31(3), 406-415. https:// doi.org/10.1177/0890334415585078

Jin, J., Song, J., Ren, F., Zhang, H., Xie, Y., Ma, J. and Li, X. (2016). Investigation of Growth PhaseDependent Acid Tolerance in Bifidobacteria longum BBMN68. Current Microbiology, 73(5), 660-667. https://doi.org/10.1007/s00284-016-1111-z

Jose, N.M., Bunt, C.R. and Hussain, M.A. (2015) Implications of Antibiotic Resistance in Probiotics. Food Reviews International, 31(1), 52-62. https:// doi.org/10.1080/87559129.2014.961075

Katayama, T. (2016). Host-derived glycans serve as selected nutrients for the gut microbe: human milk oligosaccharides and bifidobacteria. Bioscience, Biotechnology, and Biochemistry, 80(4), 621-632. https://doi.org/10.1080/09168451.2015.1132153

Kergourlay, G., Messaoudi, S., Dousset, X. and Prevost, H. (2012). Genome Sequence of Lactobacillus salivarius SMXD51, a Potential Probiotic Strain Isolated from Chicken Cecum, Showing AntiCampylobacter Activity. Journal of Bacteriology, 194(11), 3008-3010. https://doi.org/10.1128/ JB.00344-12

Kozak, K., Charbonneau, D., Sanozky-Dawes, R. and Klaenhammer, T. (2015). Characterization of bacterial isolates from the microbiota of mothers , breast milk and their infants. Gut Microbes, 6(6), 341-351. https:// doi.org/10.1080/19490976.2015.1103425

Kumar, H., Toit, E.D., Kulkarni, A., Aakko, J., LInderborg, K.M., Zhang, Y., Nicol, M.P., Isolauri, E., Yang, B., Collado, M.C., Salminen, S. and Taylor, M. (2016). Distinct Patterns in Human Milk Microbiota and Fatty Acid Profiles Across Specific Geographic Locations. Frontiers in Microbiology, 2016, 1-12. https://doi.org/10.3389/ fmicb.2016.01619

Lahtinen, S., Ouwehand, A.C., Salminen, S. and Wright, A.V. (Eds.) (2012). Lactic Acid Bacteria. Microbiological and Functional Aspects. $4^{\text {th }}$ ed. USA: CRC Press.

LaTuga, M.S., Stuebe, A. and Seed, P.C. (2014). A review of the source and function of microbiota in breast milk. Seminars in Reproductive Medicine, 32 (1), 68-73. https://doi.org/10.1055/s-0033-1361824 
Martín, R., Jiménez, E., Heilig, H., Fernández, L., Marín, M.L., Zoetendal, E.G. and Rodríguez, J.M. (2009). Isolation of bifidobacteria from breast milk and assessment of the bifidobacterial population by PCRdenaturing gradient gel electrophoresis and quantitative real-time PCR. Applied and Environmental Microbiology, 75(4), 965-969. https://doi.org/10.1128/AEM.02063-08

Mathur, S. and Singh, R. (2005). Antibiotic resistance in food lactic acid bacteria - A review. International Journal of Food Microbiology, 105(3), 281-295. https://doi.org/10.1016/j.ijfoodmicro.2005.03.008

McGuire, M.A. and McGuire, M.K. (2017). Human Milk Microbes - Summary and Research Gaps. In Mcguire, M.K., Mcguire, M.A. and Bode, L. (Eds.) Prebiotics and Probiotics in Human Milk, p. 463 468. USA: Elsevier. https://doi.org/10.1016/B978-012-802725-7.00017-8

Medjaoui, I., Rahmani, B., Talhi, M., Mahammi, F.Z., Moghtit, F.Z., Mehtar, N. and Gaouar, S.B.S. (2016). Isolation and characterization of lactic acid bacteria from human milk and newborn feces. Journal of Pure and Applied Microbiology, 10(4), 2613-2620. https://doi.org/10.22207/JPAM.10.4.17

Mokoena, M.P. (2017). Lactic acid bacteria and their bacteriocins: Classification, biosynthesis and applications against uropathogens: A mini-review. Molecules, 22(8), 1255. https://doi.org/10.3390/ molecules 22081255

Morrow, A.L. and Rangel, J.M. (2004). Human milk protection against infectious diarrhea: Implications for prevention and clinical care. Seminars in Pediatric Infectious Diseases, 15(4), 221-228. https://doi.org/10.1053/j.spid.2004.07.002

Mueller, N.T., Bakacs, E., Combellick, J., Grigoryan, Z. and Maria, G. (2015). The infant microbiome development: mom matters. Trends Molecular Medicines, 21(2), 109-117. https://doi.org/10.1016/ j.molmed.2014.12.002.The

Munita, J.M., and Arias, C.A. (2016). Mechanisms of Antibiotic Resistance. Microbiology Spectrum, 4(2), 1-24. https://doi.org/10.1128/microbiolspec.VMBF0016-2015.

Nallala, V., Sadishkumar, V. and Jeevaratnam, K. (2017). Molecular characterization of antimicrobial Lactobacillus isolates and evaluation of their probiotic characteristics in vitro for use in poultry. Food Biotechnology, 31(1), 20-41. https:// doi.org/10.1080/08905436.2016.1269289

Nemska, V., Georgieva, N. and Danova, S. (2017). Molecular Identification of Lactobacillus spp. isolated from Traditional Bulgarian Dairy Products. European Journal of Biomedical and
Pharmaceutical Sciences, 4(5), 467-473.

Öner, Ö., Aslim, B. and Aydas, S.B. (2014). Mechanisms of Cholesterol-Lowering Effects of Lactobacilli and Bifidobacteria Strains as Potential Probiotics with their bsh gene analysis. Journal of Molecular Microbiology and Biotechnology, 24, 1218. https://doi.org/10.1159/000354316

Pannaraj, P.S., Li, F., Cerini, C., Bender, J.M., Yang, S., Rollie, A., Adisetiyo, H., Zabih, S., Lincez, P.J., Bittinger, K., Bailey, A., Bushman, F.D., Sleasman, J.W. and Aldrovandi, G.M. (2017). Association between breast milk bacterial communities and establishment and development of the infant gut microbiome. JAMA Pediatrics, 171(7), 647-654. https://doi.org/10.1001/jamapediatrics.2017.0378

Pessione, E. (2012). Lactic acid bacteria contribution to gut microbiota complexity: lights and shadows. Frontiers in Cellular and Infection Microbiology, 2012, 1-15. https://doi.org/10.3389/ fcimb. 2012.00086

Pisano, M.B., Viale, S., Conti, S., Fadda, M.E., Deplano, M., Melis, M.P., Deiana, M. and Cosentino, S. (2014). Preliminary Evaluation of Probiotic Properties of Lactobacillus Strains Isolated from Sardinian Dairy Products. BioMed Research International, 2014, 286390. https:// doi.org/10.1155/2014/286390

Posse, J.L., Dios, P.D. and Scully, C. (Eds.) (2017). Oral Bacteria Transmissible by Saliva and Kissing. In Saliva Protection and Transmissible Diseases, p. 1928. USA: Academic Press. https://doi.org/10.1016/ B978-0-12-813681-2.00002-0

Quinto, E.J., Jiménez, P., Caro, I., Tejero, J., Mateo, J. and Girbés, T. (2014). Probiotic Lactic Acid Bacteria: A Review. Food and Nutrition Sciences, 5 (18), 1765-1775. https://doi.org/10.4236/ fns. 2014.518190

Rajili-Stojanovic, M. and Vos, W.M.D. (2014). The first 1000 cultured species of the human gastrointestinal microbiota. FEMS Microbiology Reviews, 38(5), 996 -1047. https://doi.org/10.1111/1574-6976.12075

Ramasamy, T.K. and Suyambulingam, K. (2015). Molecular characterization of Lactobacillus spp., from Indian curd and its Antagonistic effects on uropathogens of Diabetic patients. International Research Journal of Biological Sciences, 4(8), 1422.

Ranadheera, C.S., Evans, C.A., Adams, M.C. and Baines, S.K. (2014). Effect of dairy probiotic combinations on in vitro gastrointestinal tolerance, intestinal epithelial cell adhesion and cytokine secretion. Journal of Functional Foods, 8, 18-25. https://doi.org/10.1016/j.jff.2014.02.022

(C) 2019 The Authors. Published by Rynnye Lyan Resources 
Reis, N.A., Saraiva, M.A.F., Duarte, E.A.A., Carvalho, E.A.D., Vieira, B.B. and Evangelista-Barreto, N.S. (2016). Probiotic properties of lactic acid bacteria isolated from human milk. Journal of Applied Microbiology, 121(3), 811-820. https:// doi.org/10.1111/jam.13173

Rodriguez, J.M. (2014). The Origin of Human Milk Bacteria: Is There a Bacterial Entero-Mammary Pathway during Late Pregnancy and Lactation? Advances in Nutrition: An International Review Journal, 5(6), 779-784. https://doi.org/10.3945/ an.114.007229

Sallam, M.K., Wali, I.E. and Attia, A.E.F.M.H. (2015). Isolation of Lactobacilli and Bifidobacteria Species from Human Breast Milk. The Egyptian Journal of Medical Microbiology, 24(3), 69-73. https:// doi.org/10.12816/0024931

Scariati, P.D., Grummer-Strawn, L.M. and Fein, S.B. (1997). A Longitudinal Analysis of Infant Morbidity and the Extent of Breastfeeding in the United States. Pediatrics, 99(6), e5. https://doi.org/10.1542/ peds.99.6.e5

Serrano-Niño, J.C., Solís-Pacheco, J.R., GutierrezPadilla, J.A., Cobián-García, A., Cavazos-Garduño, A., González-Reynoso, O., and Aguilar-Uscanga, B.R. (2016). Isolation and Identification of Lactic Acid Bacteria from Human Milk with Potential Probiotic Role. Journal of Food and Nutrition Research, 4(3), 170-177.

Shi, L.H., Balakrishnan, K., Thiagarajah, K., Mohd Ismail, N.I. and Yin, O.S. (2016). Beneficial properties of probiotics. Tropical Life Sciences Research, 27(2), 73-90. https://doi.org/10.21315/ tlsr2016.27.2.6

Shokryazdan, P., Sieo, C.C., Kalavathy, R., Liang, J.B., Alitheen, N.B., Faseleh Jahromi, M. and Ho, Y.W. (2014). Probiotic Potential of Lactobacillus Strains with Antimicrobial Activity against Some Human Pathogenic Strains. BioMed Research International, 2014, 1-16. https://doi.org/10.1155/2014/927268

Sornplang, P., Sakulsawasdiphan, K., Piyadeatsoontorn, S. and Surasorn, B. (2016). Antimicrobial susceptibility of lactic acid bacteria isolated from human and food-producing animal feces in Khon Kaen Province, Thailand. Tropical Animal Health and Production, 48(8), 1739-1745. https:// doi.org/10.1007/s11250-016-1116-4

Soto, A., Martin, V., Jimenez, E., Mader, I., Rodriguez, J.M. and Fernandez, L. (2014). Lactobacilli and Bifidobacteria in Human Breast Milk: Hepatology and Nutrition, 59(1), 78-88. https://doi.org/10.1097/ MPG.0000000000000347
Thakur, N., Rokana, N. and Panwar, H. (2016). Probiotics: Selection criteria, safety and role in health and disease. Journal of Innovative Biology, 3 (1), 259-270.

Tormo, H., Lekhal, D.A.H. and Roques, C. (2015). Phenotypic and Genotypic Characterisation of Lactic Acid Bacteria Isolated from Raw Goat Milk and Effect Of Farming Practices on the Dominant Species of Lactic Acid Bacteria. International Journal of Food Microbiology, 210, 9-15. https:// doi.org/10.1016/j.ijfoodmicro.2015.02.002

Toscano, M., Grandi, R. De, Grossi, E. and Drago, L. (2017). Role of the human breast milk-associated microbiota on the newborns' immune system: A mini review. Frontiers in Microbiology, 2017, 1-5. https://doi.org/10.3389/fmicb.2017.02100

Vinderola, G., Gueimonde, M., Gomez-gallego, C., Defederico, L. and Salminen, S. (2017). Correlation between in vitro and in vivo assays in Selection of Probiotics from Traditional Species of Bacteria. Trends in Food Science and Technology, 68, 83-90. https://doi.org/10.1016/j.tifs.2017.08.005

Walker, W.A. and Iyengar, R.S. (2015). Breast milk, microbiota, and intestinal immune homeostasis. Pediatric Research, 77(1), 220-228. https:// doi.org/10.1038/pr.2014.160

Wang, M., Li, M., Wu, S., Lebrilla, C. B., Chapkin, R. S., Ivanov, I. and Donovan, S.M. (2016). Fecal Microbiota Composition of Breast-fed Infants is Correlated with Human Milk Oligosaccharides Consumed. Journal of Pediatric Gastroenterology and Nutrition, 60(6), 825-833.

Wang, X., Lu, H., Feng, Z., Cao, J., Fang, C., Xu, X., Zhao, L. and Shen, J. (2017). Development of human breast milk microbiota-associated mice as a method to identify breast milk bacteria capable of colonizing gut. Frontiers in Microbiology, 2017, 1-13. https:// doi.org/10.3389/fmicb.2017.01242

Wedajo, B. (2015). Lactic Acid Bacteria: Benefits, Selection Criteria and Probiotic Potential in Fermented Food. Journal of Probiotics and Health, 3, 129. https://doi.org/10.4172/2329-8901.1000129 